\title{
High School Mathematics Learning Transfer and Academic Evaluation Based on Core Literacy
}

Youling Zhang: School of Mathematical Sciences, University of Jinan, Jinan, Shandong 250022, P R China.

Yibing Sun: School of Mathematical Sciences, University of Jinan, Jinan, Shandong 250022, P R China.

"Zhenlai Han: School of Mathematical Sciences, University of Jinan, Jinan, Shandong 250022, P R China.

Shurong Sun: School of Mathematical Sciences, University of Jinan, Jinan, Shandong 250022, P R China.

ABSTRACT: "Core Literacy" and "Learning Transfer" are hot topics in the education field. Through the questionnaire analysis of the innovative class students and ordinary class students in Shandong Experimental Middle School. Through the high school mathematics transfer law application questionnaire, the relationship between the score and the migration ability is analyzed. Through the questionnaire of the core literacy of high school mathematics, the relationship between the score and the core literacy was analyzed. Learning transfer ability directly affects the formation of core literacy, so it is necessary to improve core literacy according to the theory of learning transfer.

Key words: Core accomplishment, Study transfer, Academic evaluation.

\section{Introduction}

In 2014, the Ministry of Education issued the "Opinions on Comprehensively Deepening Curriculum Reform and Implementing the Fundamental Tasks of Lide Shuren", which requires research and development of core literacy systems and academic quality standards for students. Professor Ma Yunpeng defines the core literacy of mathematics as: the comprehensive ability of students to learn mathematics with specific meaning (Ma, 2015). The general high school mathematics curriculum standards (2017 edition) mentioned that the core literacy of the discipline is a concentrated expression of the value of educating people, and it is the correct value, essential character and key ability gradually formed by students through subject learning. The core literacy of mathematics includes: mathematical abstraction, logical reasoning, mathematical modeling, visual imagination, mathematical operations and data analysis. The core literacy of these mathematics disciplines is relatively independent and intertwined, and is an organic whole.The mathematics knowledge in the high school stage is wider, more difficult, and the concept is more abstract. Therefore, many students can't adapt to this change when they first enter the high school stage, and their math scores are not ideal. If teachers simply carry out the sea tactics, they will only have a vicious circle. Therefore, in the teaching process of high school mathematics, if you can effectively improve the students' ability to move, you can improve classroom efficiency, improve mathematics scores, and promote students' core mathematics.

Vol. 1 , No. 2 pp. $22-25$

Email: hanzhenlai@163.com

Funding: This study received no specific

Acknowledgment: This paper is the stage achievement of Jinan University Graduate Education Innovation Project "Research on Education Quality for Professional Degrees in Shandong Province under the Backgrou "Double first-class"Construction" (No. JDY1601) and "Research on Constuction Implementation of Quality Cuarante Systen Graduate Edheation (No. JDY1707).

Article History:

Received: 1 October 2018

Revised: 24 October 2018

Accepted. 19 November 2018

() 2018 by the authors; licensee Academic Publishing Group 


\section{High School Mathematics Learning Transfer Based on Core Literacy}

One of the important indicators of effective mathematics teaching is whether students' mathematics learning can move from one problem to another, moving from one situation to another, from school classroom to social practice (Tu Rongbao, 2006). Learning transfer refers to the effect of learning on another type of learning, or the impact of learned experience on completing other activities. "Teaching for migration" has become a popular slogan for today's education. Migration is an important part of mathematics learning. There are a lot of migrations in mathematics learning, which makes students positively migrate in the process of mathematics learning and avoid negative migration, which can greatly improve teaching efficiency.

In order to make the research results more reliable and scientific, the author uses the "high school students' mathematical migration law.The questionnaire is designed to investigate the students' use of the migration rules. The questionnaires are all single-choice questions, with a total of 14 questions. Each question has 3 options. The scoring rules for all the multiple-choice questions are assigned sequentially. $5,4,3$. The questionnaire is divided into 4 dimensions. Using these four aspects, a questionnaire survey was conducted among the students. In December 2018, a questionnaire was distributed to 1 regular classes and linnovation classes in the third grade of Shandong Experimental High School. 100copies, 100 copies were recovered, and100valid questionnaires were conducted. A preliminary data analysis was conducted for an innovation class and a regular class. The results of the analysis are shown in Table 1:

Table-1. Quantitative Analysis of Learning transfer

\begin{tabular}{lll}
\hline Statistics & $\begin{array}{l}\text { Innovation } \\
\text { class }\end{array}$ & $\begin{array}{l}\text { Regular } \\
\text { class }\end{array}$ \\
$\mathrm{N} \quad$ & 50 & 50 \\
Mean $\quad$ Valid & 0 & 0 \\
Median & 64.6200 & 56.0800 \\
Moderator & 65.0000 & 56.0000 \\
Standard deviation & 65.00 & $56.00^{\mathrm{a}}$ \\
Variance & 3.31902 & 5.16993 \\
Minimum value & 11.016 & 26.728 \\
Maximum value & 56.00 & 42.00 \\
a. There are multiple modes. Display minimum \\
\hline \multicolumn{3}{l}{} \\
\hline
\end{tabular}

The average math score of the innovation class is higher than the average grade of the ordinary class. It can be clearly seen from Table 1 that the average value of the migration water of the innovation class is larger than that of the ordinary class. This also directly indicates that students with better grades in the innovation class have stronger mathematics learning transfer ability.

International Journal of Educational Studies Vol. 1, No. 2 pp. $22-25$

2018

DOI: 10.53935/2641-533x.v1i2.18

"Corresponding Author: Zhenlai Han Email: hanzhenlai@163.com Funding: This study received no specific financial support.

Acknowledgment: This paper is the stage achievement of Jinan University Graduate Education Innovation Project "Research on Evaluation Criteria and System of Graduate Education Quality for Professional Degrees in Shandong Province under the Background in "Dhandong Province under the Background of "Double-first-class"Construction" (No. JDY1601) and "Research on Construction and Implementation of Quality Guarantee System for Graduate Education of Master of Education" (No. JDY1707).

Article History

Received: 1 October 2018

Revised: 24 October 2018

Accepted: 19 November 2018

Published: 13 December 2018

(C) 2018 by the authors; licensee Academic Publishing Group

\section{High School Mathematics Evaluation Based on Core Literacy}

As stated in the fact that "literacy itself is learned in a favorable learning environment" (Rychen and Salganik, 2001), "literacy" can be concretely implemented, available for teaching and learning, and can be measured and quantified. It is not innate, but It can be learned, designed and cultivated through education.

The author designed six questions by designing the "High School Students' Mathematical Core Literacy Survey Questionnaire". Each topic focuses on a core literacy, and six topics focus on six topics.

The two key words of academic evaluation are "must have character" and "key ability". We believe that it is necessary to examine the core literacy of students' mathematics. The essential character is qualitative evaluation and procedural evaluation. The key ability is based on quantitative evaluation and summative evaluation (Yu Ping, 2018).

Professor Yu Ping suggested that in the preparation of the topic, a two-way breakdown table can be used for analysis. The first column is the title number, the first behavior is the six mathematical core competences, and the second row represents the three levels of the six key capabilities (Yu Ping, 2018). According to Professor Yu Ping's thought, a two-way breakdown of my questionnaire topic was drawn, as shown in Table 2: 
Table-2. Binocular list

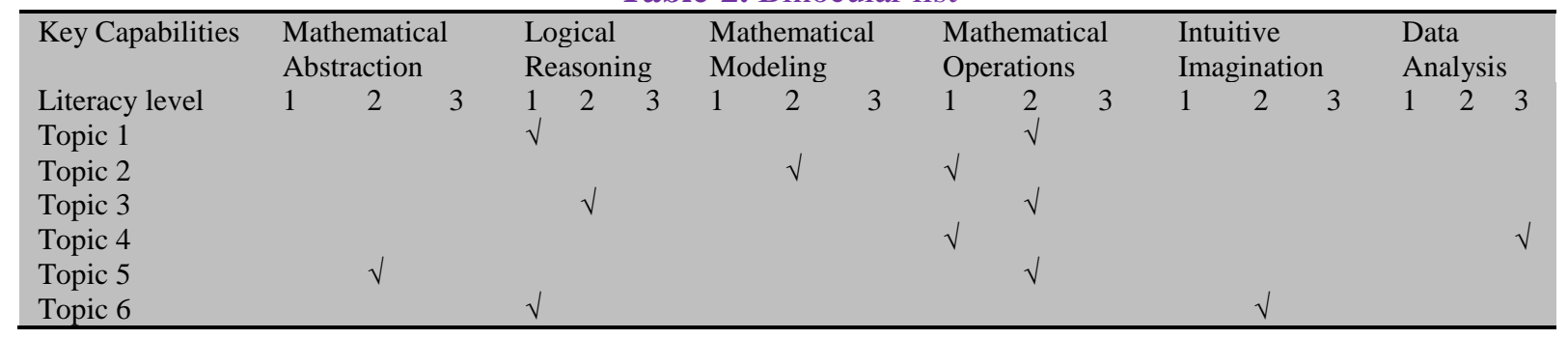

The score for each of the six questions is set to 5 and the total score is 30 . The results of the analysis are shown in Table 3:

\begin{tabular}{lll}
\multicolumn{2}{l}{ Table-3. Quantitative Analysis of Core Literacy } \\
\hline \multicolumn{2}{l}{ Statistics } \\
& $\begin{array}{l}\text { Innovation } \\
\text { class }\end{array}$ & $\begin{array}{l}\text { Regular } \\
\text { class }\end{array}$ \\
$\mathrm{N} \quad$ Valid & 50 & 50 \\
Mean $\quad$ Missing & 0 & 0 \\
Median & 28.9000 & 24.1000 \\
Moderator & 30.0000 & 25.0000 \\
Standard deviation & 30.00 & 25.00 \\
Variance & 2.32335 & 4.81176 \\
Minimum value & 5.398 & 23.153 \\
Maximum value & 20.00 & 10.00 \\
\hline
\end{tabular}

The average math score of the innovation class is higher than the average grade of the regular class. From the table, we can see that the average value of the innovation class is 28.9 , while the average value of the innovation class is 24.1. The average score of the six questions is higher than that of the ordinary class. Through the migration analysis above, the migration ability of the innovation class is higher than that of the ordinary class. A survey of the six key competencies of core literacy found that the formation of the six key competencies of the innovation class was much higher than that of the regular class. This shows that students' ability to transfer mathematics directly affects students' key abilities. If students have strong learning ability, they can transfer old knowledge to new knowledge or summarize and reflect on the questions used. Such migration behavior directly affects students' key competencies. Therefore, we need to develop students' ability to move. In turn, the core literacy of core students will be enhanced to make them better adapted to society.

\section{Use Migration Theory to Enhance Core Literacy}

\subsection{Migrating from Old Knowledge to Known Knowledge}

Abstract the collection from the function, by reviewing the collection knowledge, and then introducing the definition of the high school function. The concept of high school function is the deepening of the concept of junior high school function. In the high school stage, the function is not only a model that describes the dependencies between variables and variables, but the function concept is a special mapping between index sets. In our concept teaching of high school functions, we migrated from the function definition of junior high school to the definition of high school function. In this way, previous learning can affect subsequent learning, which is called forward migration. Through the forward migration, students not only have an intuitive and abstract understanding of the function, but also promote the improvement of the core literacy of students' mathematical abstraction (Zhang Qinglin and Wang Yongming, 1998).

\subsection{Guide Student Analogy to Promote the Occurrence of Migration}

The general theory of learning transfer theory points out that generalization is a statement or understanding of a relationship. It can also be called a principle, a law or a law. According to this theory, the key to generating migration is that learners summarize the commonalities between them in two activities (Zhang Chengfen, 2000). Therefore, we need to summarize and analogize the image and nature of the logarithmic function and the exponential function to promote the active migration of students. In 


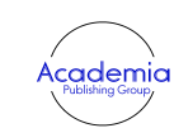

International Journal of Educational Studies Vol. 1, No. 2 pp. $22-25$

2018

DOI: 10.53935/2641-533x.v1i2.18

Corresponding Author: Zhenlai Han

Email: hanzhenlai@163.com

Funding: This study received no specific

financial support.

Acknowledgment: This paper is the stage achievement of Jinan University Graduate Education Innovation Project "Research on Evaluation Criteria and System of Graduate Education Quality for Professional Degrees in Education Quality for Professional Degrees in Shandong Province under the Background of "Double-first-class"Construction" (No. JDY1601) and "Research on Construction and Implementation of Quality Guarantee System for Graduate Education of Master of Education" (No. JDY1707).

Article History

Received: 1 October 2018

Revised: 24 October 2018

Accepted: 19 November 2018

Published: 13 December 2018

() 2018 by the authors; licensee Academic

Publishing Group mathematics learning, there is a lot of knowledge that has a common principle. Therefore, in the process of teaching mathematics, through the generalization of knowledge, help students form a knowledge system. Students can do the same in the process of doing the problem. Help students form the key skills of mathematics.

\subsection{Select Appropriate Teaching Media and Create a Learning Environment Similar to the Application Context}

Nowadays, with the development of information technology, we must properly apply modern teaching media or a combination of multiple media to create a learning environment similar to the actual problem situation (Xu Dan, 2011). We all know that similar problems are easy to establish associations. If the learning situation and the application context of the knowledge content learned in the future are similar, then it is easy to establish associations and generate learning migration.In the classroom, you can first use the geometric drawing board and super drawing board to improve students' interest in learning. For example, in the positional relationship between a straight circle and a circle, the teacher can use the geometric drawing board to demonstrate that the straight line intersects, intersects, and tangentially through the geometric drawing board to determine how to determine the positional relationship between the straight line and the circle. From the positional relationship between the line and the circle to the positional relationship between the circle and the circle, the student can easily determine the positional relationship between the circle and the circle. For example, students are learning the chapters of "Stereo Graphics and Planar Graphics". The courseware produced by teachers can display various colorful and solid three-dimensional graphics in life, and then you can see the corresponding flat graphics from multiple angles. The Chengling side is a peak, and the distance is different." This kind of poetic painting is born. Learning interest is a factor that can not be ignored in the study of migration. By using multimedia, the sound, picture and text are integrated into one, which will arouse students' interest and enable students to actively migrate.

\section{Conclusion}

"Teaching for migration" is a popular slogan in education today. Core literacy is also an educational hotspot in the education sector. There is an inseparable relationship between the two. Through the questionnaire, it is found that the corresponding ability of students with strong ability to migrate is also extremely strong. Therefore, in the process of teaching, it is necessary to cultivate students' generalization and review ability, and to cultivate students' core literacy through learning transfer.

\section{References}

Ma Yunpeng. (2015). Several Issues on the Core Literacy of Mathematics. Curriculum. Textbook. Teaching Methods, 9: 36-39.

Tu Rongbao. (2006). Mathematics Learning and Mathematical Migration. Journal of Mathematics Education, 15(4): $1-5$.

Rychen D S, \& Salganik L H. (2001). Defining and selecting key competencies. Hogrefe \& Huber.

Yu Ping. (2018). Objectives and Academic Evaluation of High School Mathematics Curriculum Based on Core Literacy. Curriculum, Text. Teaching Methods, 1: 80-85.

Zhang Qinglin \& Wang Yongming. (1998). Three Theories of Analogic Migration. Psychological Science, 6: 55-551.

Zhang Chengfen. (2000). Educational Psychology. Shandong Education Press.

Xu Dan. (2011). Practice and research on the cultivation of mathematics migration ability. Liaoning Normal University. 